The International Journal of Multimedia \& Its Applications (IJMA) Vol.10, No.6, December 2018

\title{
Learning Object-Oriented Programming Paradigm Via Game-Based Learning Game - Pilot STUDY
}

\author{
Wong Yoke Seng, Maizatul Hayati Mohamad Yatim and \\ Tan Wee Hoe
}

Sultan Idris Education University, Malaysia

\begin{abstract}
Traditional classroom-based learning and teaching methods though established are not effective and insufficient to deliver the object-oriented programming (OOP) to computer science undergraduates. Thus, to resolve this issue, a game-based learning approach to enhance the student's understanding and improve their learning curves was adopted. Based on the three-layered game-based learning design model, the proposed role-playing game called Odyssey of Phoenix $(\mathrm{OoP})$ was resulted. To test the performance of the $O o P$, a group of 20 students from the bachelor degree background of computer science who are in their second year were offered to participate a pilot testing to evaluate the game. The outcome of the pilot testing showed satisfactory and positive results whereby most players agreed that OoP was efficient and effective as a learning tool for them to understand and learn about the OOP paradigm.
\end{abstract}

\section{KEYWORDS}

Learning and teaching programming, Object-Oriented programming, Education, Game-based learning and teaching

\section{INTRODUCTION}

Object-oriented programming (OOP) is a fundamentally important subject required by the Information Technology (IT) industry for all computer science or Information Communications Technology (ICT) students [1]. However, teaching OOP to undergraduate students is challenging. Besides that, academician needs to find other approaches that are suitable to teach the student on the OOP subject. The paper-and-chalk based teaching method and lecture-learning-centered approach are insufficient to educate the students on the programming-related course [2].

Thus, from this research work, a two-dimensional (2D) role-playing game named Odyssey of Phoenix (OoP) was developed and proposed as the game-based learning to lead the undergraduate students to learn OOP in a simple, fun and interactive way. The design of the OoP game conceptually requires the players to solve the game stage-by-stage, whereby they can acquire the knowledge on the OOP paradigm at the end of each task. This role-playing game is crucial for inexperienced student who need to understand the OOP [3]. Furthermore, the game-based learning approach is still lacking in the literature even though computer games are considered to be efficient tools for learning OOP [4]. Therefore, the aim of this paper is to entail and confer the development of game-based learning game (2D role-playing) to learn OOP paradigm. 
The International Journal of Multimedia \& Its Applications (IJMA) Vol.10, No.6, December 2018

\section{Literature REVIEW}

\subsection{Different Types of Programming Teaching Game}

Some of the current games exercise for learn-programming such as CodeCombat, Alice 2D and Greenfoot, require students to practice and play with programming coding exercises [5]. For example, in order to advance through a story setting in CodeCombat, the player needs to have the knowledge of script languages such as python, Lua and also JavaScript and use them to compete against other players, as shown in Figure 1.0 [6]. For the second example (Figure 2.0), Alice is a three-dimensional (3D) animation programme which provides highly interactive and visualised environment for the players to construct a virtual world by inserting different levels of Java coding [7]. Meanwhile, Greenfoot (Figure 3.0) is another teaching and learning program that is developed based on Java language [8]. This text-based programming of Greenfoot which uses Java language can create sophisticated applications that match the students' expectations as well as prepare them for progression into a more general and higher level of programming environment [9].

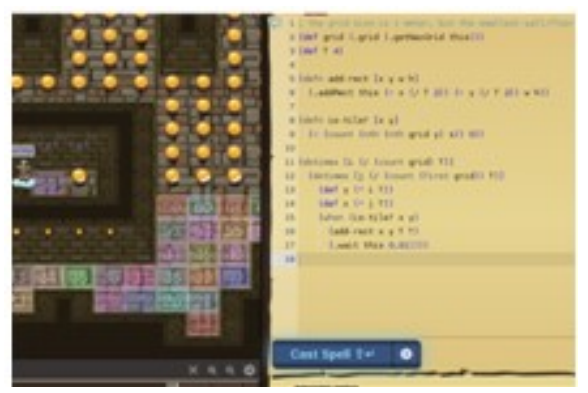

Figure 1.0 In-game coding exercises - Code Combat

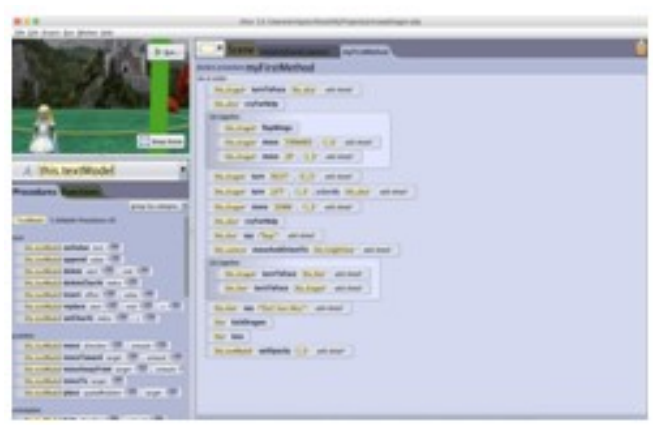

Figure 2.0 In-Game Coding Exercises - Alice

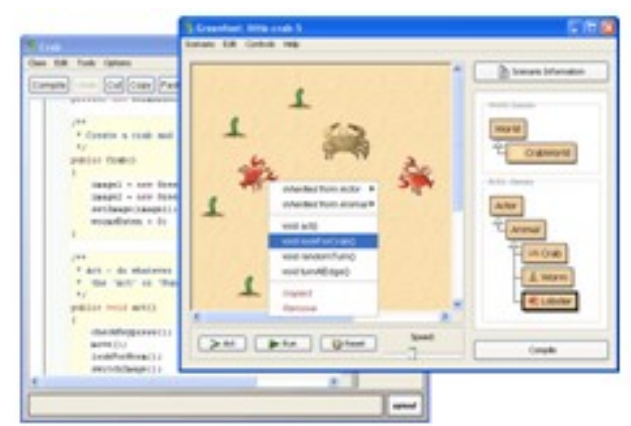

Figure 3.0 In-Game Coding Exercises - GreenfootS

The above mentioned games require programming and coding exercises [10]. Thus, the development of propriety game-based system for the learning of OOP without coding exercises is necessary. For OoP, the game-based learning game focuses on the game play experience and game mechanics to perform the learning objective, where no prior coding knowledge is required.

\subsection{Theories and Their Impact on Game-Based Learning Design}

In order to develop a critical game-based learning design, several important theories need to be considered such as Attention, Relevance, Confidence and Satisfaction (ARCS) Theory of Motivation, Cognitive Apprenticeship, Distributed Practice, Episodic Memory, Flow Theory, 
The International Journal of Multimedia \& Its Applications (IJMA) Vol.10, No.6, December 2018

Lepper's Instructional Design Principles for Intrinsic Motivation, Malone's Theory of Intrinsically Motivation Instruction, Operant Conditioning, Scaffolding, Social Learning Theory, Self-Determination Theory and The Taxonomy of Intrinsic Motivations for Learning, as listed in Table 1.0. However, different learning contexts require different combinations [11].

Table 1.0 Theories and Their Impact on Game-Based Learning

\begin{tabular}{|c|c|}
\hline Theory & Impact on Game-Based Learning Design \\
\hline $\begin{array}{l}\text { ARCS Theory of } \\
\text { Motivation }\end{array}$ & $\begin{array}{l}\text { The obtainment of learner's attention, the inclusion of relevant } \\
\text { information and the aimed of the appropriate level of challenges are } \\
\text { set as the basis so that the learner is confident. This theory provides } \\
\text { intrinsic and extrinsic motivational elements. }\end{array}$ \\
\hline Cognitive Apprenticeship & $\begin{array}{l}\text { The authenticity of setting and environment should be assured. } \\
\text { Feedback and suitable guidance should also be given based on the } \\
\text { learner's activity. }\end{array}$ \\
\hline Distributed Practice & $\begin{array}{l}\text { Spaced repetition of the game content is provided by play-out over } \\
\text { time. }\end{array}$ \\
\hline Episodic Memory & $\begin{array}{l}\text { Evoke learners' emotion to more richly encode the lesson from the } \\
\text { game in memory }\end{array}$ \\
\hline Flow Theory & $\begin{array}{l}\text { Maintaining the learners' state of interest continuously. The system } \\
\text { also provides to the suitable challenge level. }\end{array}$ \\
\hline $\begin{array}{l}\text { Lepper's Instructional } \\
\text { Design Principles for } \\
\text { Intrinsic Motivation }\end{array}$ & $\begin{array}{l}\text { Include element of learner control, challenges, curiosity and } \\
\text { contextualization. }\end{array}$ \\
\hline $\begin{array}{l}\text { Malone's Theory of } \\
\text { Intrinsically Motivation } \\
\text { Instruction }\end{array}$ & $\begin{array}{l}\text { Elements of learners' fantasy, game challenges and players' curiosity } \\
\text { are included as the motivation instruction. }\end{array}$ \\
\hline Operant Conditioning & $\begin{array}{l}\text { Appropriate incentives (badges, rewards, points) in a variable basis } \\
\text { are provided to maintain learners' interest }\end{array}$ \\
\hline Self-Determination Theory & $\begin{array}{l}\text { The learner will have the chance for autonomy, feeling of competence } \\
\text { and relevancy. }\end{array}$ \\
\hline Social Learning Theory & $\begin{array}{l}\text { Model desired behavior so learner observes and internally processes } \\
\text { the desired behavior. }\end{array}$ \\
\hline Scaffolding & $\begin{array}{l}\text { Typically, sufficient or greater guidance is provided for the beginners. } \\
\text { As the players progress, less guidance is given until a point when the } \\
\text { learner can solve the given tasks independently. }\end{array}$ \\
\hline $\begin{array}{l}\text { The Taxonomy of Intrinsic } \\
\text { Motivations for Learning }\end{array}$ & $\begin{array}{l}\text { Both internal and external elements such as game control, game } \\
\text { curiosity, fantasy, competition and recognition are set as motivations. }\end{array}$ \\
\hline
\end{tabular}

In the development of OoP, critical theories such as ARCS theory of motivation [12], Cognitive Apprenticeship [13], Distributed Practice [14], Episodic Memory [15], Flow Theory [16], The Taxonomy of Intrinsic Motivations for learning [17], Self-determination Theory [18] and Operant Conditioning [19] and are included to ensure the entire learning process in the game is simple, motivating, fun and interactive. 
The International Journal of Multimedia \& Its Applications (IJMA) Vol.10, No.6, December 2018

\section{Conceptual Framework}

The learning subject, OOP not only has improved the development of computer science and technology, it is also a software pattern that practiced by most IT experts [20]. The programming paradigm of OOP is based on several so-called mechanisms which include, interactive behavior among the objects, classes hierarchy and well-structured objects [21]. Learning and understanding OOP paradigm can be challenging to certain students. However, it is unavoidable as OOP is fundamentally required for the IT industry of both students and professionals. In order to build the proposed conceptual framework for this research, several related theories mentioned are included based on Table 1.0. Besides all the relevant theories, instructional game design methodology is also included in the OoP development which focuses on the conceptualization of abstract, active experimentation, reflective observation and concrete experience [22]. Thus, the game-learning of OoP forms a challenge cycle that involves synthesis development, elicit practice and feedback. For this research, three (4) layers namely main layer (main), gameplay layer (inner), learning theory layer (middle) and presentation layer (outer), form the conceptual framework, as shown in Figure 4.0.

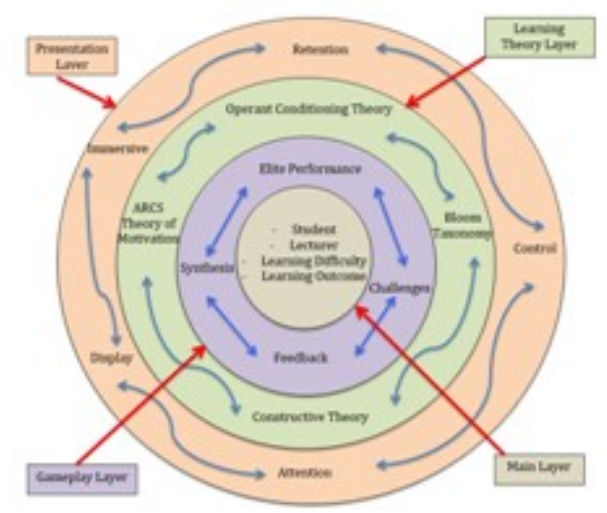

Figure 4.0 Game-Based Learning Conceptual Framework for learning OOP.

\subsection{Main Layer}

The main propose of the main layer is indicating the main research variables that required for this research. The identified research variables in main layer are student, lecturer, learning outcome and learning difficulties. The purpose of the research is to prepare and design a GBL game that used as supporting tool to learn OOP paradigm. Thus, understanding the learner or student requirement and their difficult in learning and teaching is crucial. By knowing their challenges and difficulties, the proposed GBL game able to address these challenges and difficulties effectively. As mentioned, the purpose of the proposed GBL game is used as supporting tool to help lecturer to deliver the learning content accordingly. Thus it is necessary to identify the lecturer teaching difficulties. According to several studies, some of the core issues faced by both lecturers and students on teaching and learning of OOP were as follows [2] [23] [24] [25][7]:

- Lack of programming knowledge

- Course structure

- Interest factor 
The International Journal of Multimedia \& Its Applications (IJMA) Vol.10, No.6, December 2018

By focusing on these issues, the proposed OPhoenix aims to eliminate such barriers on students, barriers on lecturers as well as barriers between students and lecturers.

\subsection{Gameplay Layer}

The gameplay layer is playing important role that proving the guideline and process for designing the game mechanics and ensure the proposed GBL game is include the appropriate game mechanics. This layer constructs by four phases in sequence such as elicit performance, challenges, feedback and synthesis. Elicit Performance means providing learning guidance with clues or hints to help learner understand and remember what they are to learn. As for the challenges, it refers to something that needs great effort to be done successfully and therefore tests a person's ability and understanding. For the feedback phase, it refers to the information about the action executed that provides an idea of whether the action is good or bad. As or the synthesis phase, it give learners an opportunity to demonstrate that they have learned the new information to this point and are ready to proceed to the next part of the progress. Every game mechanics are given a task or mission with hints and guidance of the mission completion purpose. Player needs to obtain the hints or clues by interaction with Non-player character (NPC) in the game world. When player executing the clue or hints, different difficulty challenges will be include in the process. All the interaction and action executed by the player in the game will be given feedback to alert the player [26]. By the given feedback, the player will be able to react and decide what to do next. By completing each hints and clues, player able to synthesize the completed hints and tasks to decide how to proceed to next clues for hints.

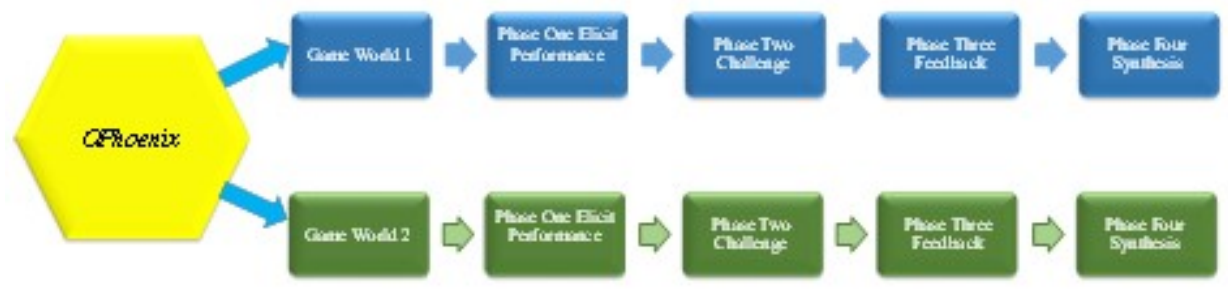

Figure 4.1 Gameplay of proposed GBL game.

\subsection{Learning Theory Layer}

There are total of four learning theories had been include to this layer such as Constructive Theory, Bloom Taxonomy Theory, ARCS of Motivation Theory and Operant Conditioning Theory. The reason to include this layer to this proposed conceptual framework because it is important to include the learning theories to ensure the proposed GBL game are well develop with the appropriate learning context and content for the learner. For example, constructive theory used the learning experienced based on the pilot testing to improve of proposed GBL game. As the constructive theory consisted of four phases such as orientation phase, brainstorming, restructuring of ideas, application ideas and application reflection, these phases were included in the developed GBL game throughout all the proposed gameplays. For the Bloom Taxonomy learning theory was used to retain the students' learning interest, thus all levels were maintained in the gameplay design as a form of game balancing experiences. Besides that, the operant conditional theory was applied to improve the game design of proposed GBL game in order to capture the learners' conscious control and spontaneous action during the gameplay. For the last learning theory, the ARCS motivational model aims to retain students' interest and 
The International Journal of Multimedia \& Its Applications (IJMA) Vol.10, No.6, December 2018 motivation to play the proposed GBL game for improving the understanding about OOP paradigm.

\subsection{Presentation Layer}

The last layer of the proposed GBL Driven Framework is presentation layer which consists of five elements such as attention, retention, control, discovery and immersive. The presentation layer is defining the requirements of the game User Interface design. The ultimate goal for the presentation layer is to create immersive game user interface to ensure the player able to play the game properly at the same time able to earn OOP paradigm. In order to achieved the ultimate goal, several all the elements from this layer need to applied to the development of the propose GBL game.

\section{Development Of Odyssey Of Phoenix}

The Odyssey of Phoenix (OoP) employed the Role-Playing concept to make it more exciting and engaging. OoP is also regarded as one of the few first mobile games that learns OOP.

All the game assets used in OoP are self-drawn 2D images and characters to provide immersive learning to the players. There are three (3) created jetties and five (5) main destinations, namely Crystal Cave, Abandoned Warehouse, Bandit Cave, Underground Min and Bandit Cave, available in the game world of OoP. To travel from one area to another, the player can easily click on the area icons. Then, the area name will be shown when clicked. To ensure easy-to-use interface for gaming purpose, the interface of OoP is designed based on mobile applications. Furthermore, the game storyline is attractively narrated with pleasant game graphic, interesting sound and music, eye-catching animation as well as nice character design.

\section{Game World Design}

As mentioned, OoP is a 2D mobile game designed for the players to learn OOP concept and paradigm. By following the game flow, the players are set to learn how to construct a virtual spaceship by performing and completing all the game quests. The following section entails the storyline for OoP:

"The game story begins in an apocalypse galaxy, at one of the planets. The main character in OoP is Kyle, the second prince of the Exora planet. Being treated as a threat to the King's throne, he was defamed and charged with treason. For his sentence, he was exiled from his own home planet forever. However, while on his way to the prison planet, his transportation space shuttle was attacked and soon crashed landed on an unknown area of the prison planet. Kyle was saved by a kind and mysterious old man. As a result from the crash, he suffered from amnesia. The warmth and kind presence of the old man made Kyle feel safe. Slowly, Kyle recovered from his injury. Soon after, the old man revealed his plan to build a spacecraft as a mean to escape this planet.

The first task of the game was collection of data. Kyle was tasked to reclaim a logbook containing critical information for the spacecraft parts from the bandits. By completing each task, Kyle managed to obtain the required materials to build parts of the spacecraft. During his journey on the assembly of his escape spacecraft, Kyle regained his memory and vowed to take back his own home planet from the corrupted. Finally, with the space shuttle completed, the old man who 
The International Journal of Multimedia \& Its Applications (IJMA) Vol.10, No.6, December 2018 saved Kyle died of a natural cause. After bidding farewell to the old man, Kyle shed his final tears and took off with their spacecraft, Phoenix. Kyle landed safely back to his home planet and secretly planned to start a revolution. In the next phase, he sought loyal allies within the town and gradually built his military strength by recruiting mercenaries and soldiers. After months, the military strength was strong and stable for a revolution. At the end, the game reached its final chapter when Kyle faced his betrayer, who was also his own brother, Vesper. Kyle defeated Vesper and his men. However, it was revealed that the true mastermind behind of the betrayal was his uncle. But he was long gone before the war fire ended. After the revolution, Vesper was not exiled but sentenced to be imprisoned within his room because he was used and manipulated by his own uncle. The story ended with his uncle still at large, but, his home planet was finally in peace."

OoP indeed provides an interesting storyline to its players. Furthermore, OoP is also a standalone programme in which the players can choose to play and learn at his own pace and time. By going through the game, players will understand the OOP fundamental and concept with the gaming part retaining their interest and enhancing their learning curve. All basic OOP concepts and elements such as encapsulation, inheritance and polymorphism are found in the game. In addition to that, some basic programming concepts are included in the game to improve the learning of OOP. Each quest is embedded with programming ideas and well-distributed through the two planets in the game. With all those interesting elements, OoP is set to be a promoter to smoothen the learning path of OOP concepts.

From the first planet, the basic OOP paradigm is indirectly taught to the players. In this first task, Kyle (or the player) needs to collect materials and resources to build a spaceship. The obtained logbook will provide hints such as the amount of materials, location, method and description of crafting. The obtained hints represent the collection of a class and object (encapsulation) in the OOP design. Upon the success of parts' crafting, the pseudocode obtained from this process is one of the OOP learning processes (Figure 5.0). Furthermore, there are eight (8) items to be crafted to build the spaceship. These items include craft's wings, cargo bay, craft's tail, main gear, nose gear, main engine, obituary engine and flying deck. Each crafting quest is designed to make sure that the player comprehends the concepts of OOP. The inheritance concept is also included in the crafting quest. For example, the main gear and nose gear are the types of gear used in this spaceship. Therefore, the resources for these two (2) items are shared. The lightweight metal and scrap metal parts are needed to build a gear. The nose gear however required extra resource such as cerusite. By collecting and using the given hints, the inheritance concept is taught to the player as he will need to figure out that that the basic and required resources can be used to build both items. But, with one (1) extra resource, another type of gear can be created or crafted. In OoP, the player will be challenged as well as rewarded for his/ her game enthusiasm, whereby he will be encouraged to proceed in learning new programming technique from time to time.

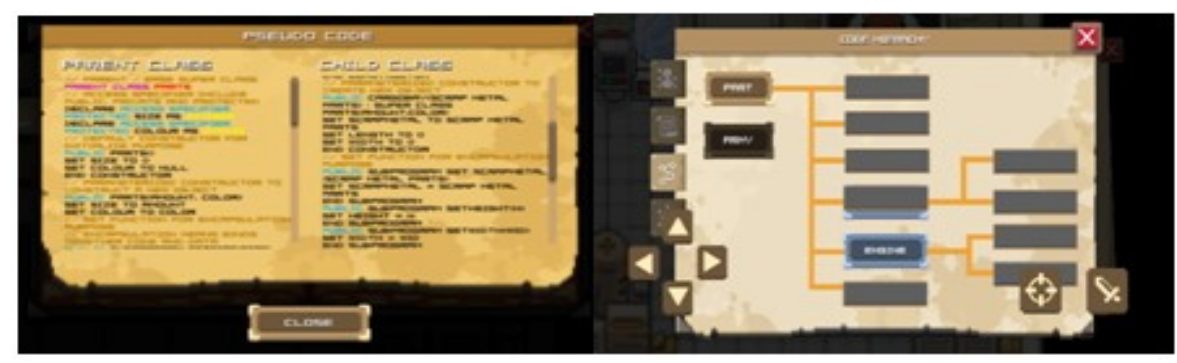

Figure 5.0 In-game Class Structure in Pseudo code and Class Hierarchy 
The International Journal of Multimedia \& Its Applications (IJMA) Vol.10, No.6, December 2018

\section{Odyssey Of Phoenix With Constructive Alignment}

The alignment of the learning outcomes with the game mechanics is very important to make sure that the gameplay and the game mechanics are suitable and effective to achieve the learning outcome. The proposed game is adapting Biggs' constructive alignment [27] to align the gameplay with learning outcomes.

There are two (2) major concepts from the constructive alignment from Biggs are shown below [28]:

- Ways to get students involve in learning process to achieve the intended objectives

- Ways to set up a teaching and learning conditions that support the learning activities

Table 2.0 - Table 4.0 and Figure 6.0 - Figure 7.0 indicate the intended learning outcome with respect to the game elements of the proposed game. This so-called constructive alignment of OoP matches the observable behavior, condition of attainment and degree of attainment (the intended outcomes) with the set game rules, targets and interactive feedback (structural elements) [29].

Table 2.0 Constructive Alignment 1

\begin{tabular}{|c|c|c|c|}
\hline Quest 2 & \multicolumn{3}{|c|}{ Outcome of extraction and alignment } \\
\hline $\begin{array}{l}\text { Extracting } \\
\text { component } \\
\text { s of } \\
\text { Learning } \\
\text { Outcome }\end{array}$ & $\begin{array}{l}\text { Observable } \\
\text { behaviour: } \\
\text { Understand class } \\
\text { creation with } \\
\text { inheritance } \\
\text { hierarchy structure } \\
\ldots\end{array}$ & $\begin{array}{l}\text { Condition of attainment: } \\
\ldots \text { that include attribute, } \\
\text { constructors and methods } \\
\ldots\end{array}$ & $\begin{array}{l}\text { Degree of Attainment: } \\
\ldots \text { to understand all the } \\
\text { class structure in pseudo } \\
\text { code }\end{array}$ \\
\hline $\begin{array}{l}\text { Setting } \\
\text { elements of } \\
\text { game }\end{array}$ & $\begin{array}{l}\text { Goal: } \\
\text { Complete the } \\
\text { hierarchy chart }\end{array}$ & $\begin{array}{l}\text { Rules of play: } \\
\text {... by completing all the } \\
\text { required parts, e.g. collect } \\
\text { required material; }\end{array}$ & $\begin{array}{l}\text { Feedback: } \\
\text { Victory - show debrief } \\
\text { that explains attainment } \\
\text { Mission fail - try again }\end{array}$ \\
\hline $\begin{array}{l}\text { Alignment } \\
\text { of Learning } \\
\text { Outcome } \\
\text { component } \\
\text { s \& game } \\
\text { elements }\end{array}$ & \multicolumn{2}{|c|}{$\begin{array}{l}\text { Intended observable behaviour that abide rules } \\
\text { of play: } \\
\text { obtain and analysing the given class and the } \\
\text { inheritance hierarchy structure } \\
\text { defeat the enemies to obtain the required } \\
\text { material } \\
\text { fail to defeat the enemies will result to minus the } \\
\text { avatar health point }\end{array}$} & $\begin{array}{l}\text { Victory debriefing: } \\
\text { Collect all the parts } \\
\text { successfully can be } \\
\text { achieved based on the } \\
\text { ability of the player to } \\
\text { collect the right amount } \\
\text { of material by defeating } \\
\text { all the enemies }\end{array}$ \\
\hline
\end{tabular}
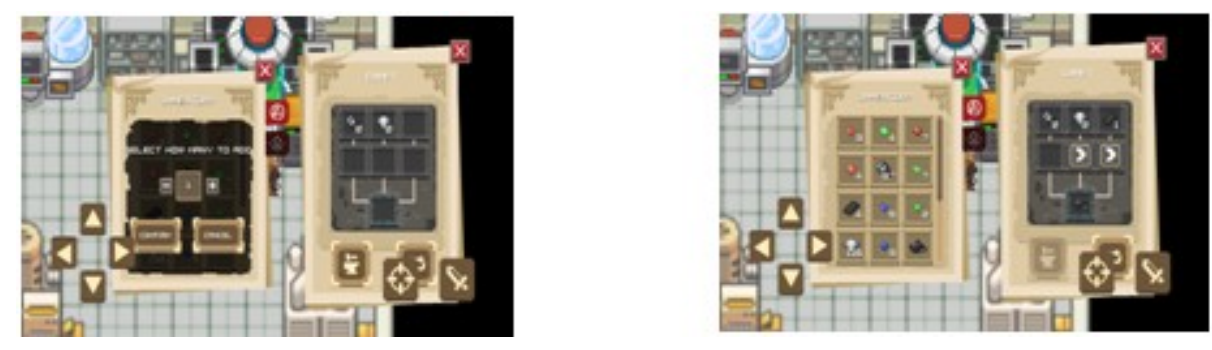

Figure 6.0 In-game Object Creation (Crafting Process)

Table 3.0 Constructive Alignment 2 
The International Journal of Multimedia \& Its Applications (IJMA) Vol.10, No.6, December 2018

\begin{tabular}{|c|c|c|c|}
\hline Figure 6.0 & \multicolumn{3}{|c|}{ Outcome of extraction and alignment } \\
\hline $\begin{array}{l}\text { Extracting } \\
\text { components } \\
\text { of Learning } \\
\text { Outcome }\end{array}$ & $\begin{array}{l}\text { Observable } \\
\text { behaviour: } \\
\text { Understand object } \\
\text { creation... }\end{array}$ & $\begin{array}{l}\text { Condition of attainment: } \\
\ldots \text { that selecting the right } \\
\text { amount of required } \\
\text { material... }\end{array}$ & $\begin{array}{l}\text { Degree of Attainment: } \\
\text {... to understand how } \\
\text { object creation based on } \\
\text { the class structure }\end{array}$ \\
\hline $\begin{array}{l}\text { Setting } \\
\text { elements of } \\
\text { game }\end{array}$ & $\begin{array}{l}\text { Goal: } \\
\text { Craft the required } \\
\text { parts }\end{array}$ & $\begin{array}{l}\text { Rules of play: } \\
\text {.. by including the } \\
\text { required material from } \\
\text { the class, e.g. provide the } \\
\text { right amount of material. }\end{array}$ & $\begin{array}{l}\text { Feedback: } \\
\text { Victory - show debrief } \\
\text { that explains attainment } \\
\text { Mission fail - try again }\end{array}$ \\
\hline $\begin{array}{l}\text { Alignment } \\
\text { of Learning } \\
\text { Outcome } \\
\text { components } \\
\text { \& game } \\
\text { elements }\end{array}$ & \multicolumn{2}{|c|}{$\begin{array}{l}\text { Intended observable behaviour that abide rules } \\
\text { of play: } \\
\text { obtain enough required material according to the } \\
\text { class structure } \\
\text { press on the add or subtract button to select the } \\
\text { material amount } \\
\text { provide insufficient material will only get the } \\
\text { craft rubbish instead the required part, required } \\
\text { to obtain again material. }\end{array}$} & $\begin{array}{l}\text { Victory debriefing: } \\
\text { Craft the required part } \\
\text { successfully can be } \\
\text { achieved based on the } \\
\text { ability of the player } \\
\text { provide the right amount } \\
\text { of material needed for } \\
\text { crafting process }\end{array}$ \\
\hline
\end{tabular}

Table 4.0 Constructive Alignment 3

\begin{tabular}{|l|l|l|l|}
\hline Figure 8.0 & \multicolumn{3}{|l|}{ Outcome of extraction and alignment } \\
\hline $\begin{array}{l}\text { Extracting } \\
\text { components } \\
\text { of Learning } \\
\text { Outcome }\end{array}$ & $\begin{array}{l}\text { Observable } \\
\text { behaviour: } \\
\begin{array}{l}\text { Understand the } \\
\text { concept of } \\
\text { polymorphism... }\end{array}\end{array}$ & $\begin{array}{l}\text { Condition of attainment: } \\
\ldots \text { that include pointers, } \\
\text { abstract class ... }\end{array}$ & $\begin{array}{l}\text { Degree of Attainment: } \\
\ldots \text { to understand all the } \\
\text { polymorphism } \\
\text { algorithms }\end{array}$ \\
\hline $\begin{array}{l}\text { Setting } \\
\text { elements of } \\
\text { game }\end{array}$ & $\begin{array}{l}\text { Goal: } \\
\text { Answer all the } \\
\text { question correctly } \\
\text { in order to get } \\
\text { required alliance to } \\
\text { attack the final boss } \\
\text { together }\end{array}$ & $\begin{array}{l}\text { Rules of play: } \\
\text { all by successfully acquire } \\
\text { answering all the question } \\
\text { correctly; }\end{array}$ & $\begin{array}{l}\text { Feedback: } \\
\text { Victory - show debrief } \\
\text { that explains attainment } \\
\text { Mission fail - try again }\end{array}$ \\
\hline $\begin{array}{l}\text { Alignment } \\
\text { of Learning } \\
\text { Outcome } \\
\text { components } \\
\text { \& game } \\
\text { elements }\end{array}$ & $\begin{array}{l}\text { Intended observable behaviour that abide rules of } \\
\text { play: } \\
\text { obtain and analyse the given question } \\
\text { moving the avatar to the direction with right } \\
\text { answer } \\
\text { providing wrong answer will fail to acquire the } \\
\text { alliance and repeat the task again. }\end{array}$ & $\begin{array}{l}\text { Victory debriefing: } \\
\text { Acquiring all the alliance } \\
\text { successfully can be } \\
\text { achieved based on the } \\
\text { ability of the player } \\
\text { answer the question } \\
\text { about all polymorphism } \\
\text { algorithms. }\end{array}$ \\
\hline
\end{tabular}

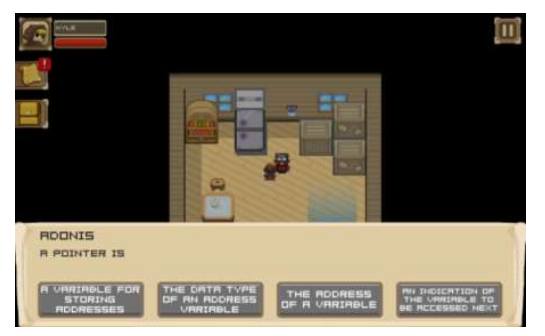

Figure 7.0 in-game Multiple Choice Question 
The International Journal of Multimedia \& Its Applications (IJMA) Vol.10, No.6, December 2018

\section{Pilot Study}

A pilot study is a preliminary study that helps researchers get an initial overview to identify how the games are developed, how the games are to be used and what are the problems encountered. Moreover, the pilot testing can help to identify the problems and their solutions before the actual launching of tools as well as improve the game instrument. The trial study conducted only included one class of students in an actual environment with twenty (20) subjects. The collection of quantitative data was performed by using the pre-test and post-test. While for the qualitative data were obtained through interviews. Suggestions to improvement the game instrument were then summarized based on both the quantitative and qualitative results obtained. The effectiveness of the proposed game and the elements in the prototype that required improvement were also identified from this trial test. The trial study was divided into two (2) parts: a pilot study to test the validity and reliability of the research instrument and the reliability of the pretest and post-test, respectively.

\subsection{Sampling for Pilot Study}

Based on the literature, a total of 10 to 12 participants were found to be sufficient for the evaluation of instrument as well as the identification of critical questions and instructions for OoP development. Therefore, for this game trial testing, a total of twenty (20) computer science students from year one programme, KDU University College, were randomly selected. The test samples/ subjects were randomised for the pilot testing, which acquired the key information before the actual research was performed [30]. The 20 participated students are divided equally in two groups, which are control group and focus group. Student who under the control group will be only participated the pre-test and post-test without playing the proposed game. However students are under focus group will be participated the pre-test and post-test with playing the proposed game.

\subsubsection{Selected Participants}

All the participated students are having the same level of knowledge before conducting the pretest. This is because all of them pass the fundamental of programming subject with minimal $\mathrm{C}$ grade.

\subsubsection{Pre-test and Post-test}

The structure of both test (pre and post) were divided to two parts. First part of the tests was designed to have four sub-sections comprised of 40 multiple-choice questions. Each sub-section possessed 10 questions, assessing concepts such as classes and objects, encapsulation, inheritance and polymorphism. Second part of the tests was designed to contain 30 fill-in-the-blank questions which covered overall OOP concept. The learning contents were intended to be identical for both tests, but the questions were designed differently. To eliminate the external influence on the proposed GBL game testing, the testing environment for these test were ensure to be identical during the conducts of experiments. The six subject experience lecturers were recorded for the validation of the pre-test and post-test using a validation form. In the validation process, the learning content, question grouping, and question design were reviewed and validated 
The International Journal of Multimedia \& Its Applications (IJMA) Vol.10, No.6, December 2018 accordingly by the lecturers to be aligned suitably with the proposed OOP paradigm learning contents such as encapsulation, inheritance and polymorphism.

\subsection{Procedure for Pilot Testing}

To identify the understanding level of selected students towards OOP before the pilot testing, both groups were given a set of pre-test questions that consisted of 40 multiple-choice questions and fill-in-the-blank questions (with a total 100 marks). The duration for the pre-test was set to be 90 minutes. After completion of the pre-test, only the focus group students were given the proposed game to play for one (1) month without disrupting their daily lesson. After 1 month of game testing, all the participated students were provided a set of post-test questions containing with 40 multiple-choice questions and fill-in-the-blank questions with a total mark of 100 , to be completed within 90 minutes as well. In order to achieve the pilot testing mentioned objectives, interview were also carried out with the selected student. The duration of interview was one (1) hour. The pre-test and post-test had been validated by six (6) subject experts who are teaching object-oriented programming for more than 7 years to ensure all the questions listed in both tests are relevant and math to the learning content.

\section{FindingS}

The pre-test and post-test scores from focus and control group are presented in section, as comparison of achievement. As can be observed, the pre-test was performed and its results were obtained before the trial of game-based learning game. The post-test was performed after one month trial of OoP. Since the pre-test and post-test questions were testing the same topics but with different scenario and question construction, the obtained results showed that majority of the post-test scores were higher compared to the pre-test scores. Ten (10) students from focus group were participated to a questionnaire and five (5) of them had been selected for interviewed to obtain their players' feedback. Most of them felt OoP was enjoyable and by playing the proposed game, the OOP paradigm could be understood relatively easier.

\subsection{Analysis of Student Performance in Control Group}

According to table 5.0, the lowest score and highest score for pre-test is 29 and 48 . As for the lowest and highest score for post-test is 28 and 53 respectively. The lowest score increase in pretest and post-test is 2 that achieved by student S2. Total of four students (S3, S6, S7, S9) obtain same score for pre-test and post-test. While the highest score increase in pre-test and post-test is 5 achieved by student S8. For the score decrement in pre-test and post test is -1 achieved by student S1 and S5. The total students that obtaining score increment is 4 out of 10 (which equal to $40 \%$ ), 4 student obtaining same score (which equal to 40\%) and only 2 student obtaining score decrement (which equal to $20 \%$ ). 
The International Journal of Multimedia \& Its Applications (IJMA) Vol.10, No.6, December 2018 Table 5.0 Pre-Test and Post-Test result from Control Group

\begin{tabular}{|c|c|c|}
\hline Student & Pre-Test & Post-Test \\
\hline S1 & 45 & 44 \\
\hline S2 & 45 & 47 \\
\hline S3 & 41 & 41 \\
\hline S4 & 38 & 41 \\
\hline S5 & 29 & 28 \\
\hline S6 & 40 & 40 \\
\hline S7 & 43 & 43 \\
\hline S8 & 48 & 53 \\
\hline S9 & 43 & 43 \\
\hline S10 & 34 & 37 \\
\hline
\end{tabular}

Table 6.0 Paired Sample Statistic for Pre-Test and Post-Test from Control Group

\begin{tabular}{llllll}
\hline & & \multicolumn{2}{c}{ Paired Sample Statistics } & \\
\cline { 3 - 5 } & & Mean & $\mathrm{N}$ & Std. Deviation & Std. Error Mean \\
\hline Pair 1 & Pre-test & 40.6 & 10 & 6.240 & 1.974 \\
& Post-test & 41.7 & 10 & 6.929 & 2.191 \\
\hline
\end{tabular}

Paired sample t-test is conducted for testing the significant mean score in pre-test and post-test. The analysis result of paired sample t-test is shown $\mathrm{n}$ table 6.0. Form the table 6.0, the mean score for control group is 1.1 (from $40.6-41.7$ ).

Table 7.0 Paired t-test for Pre-Test and Post-Test from Control Group

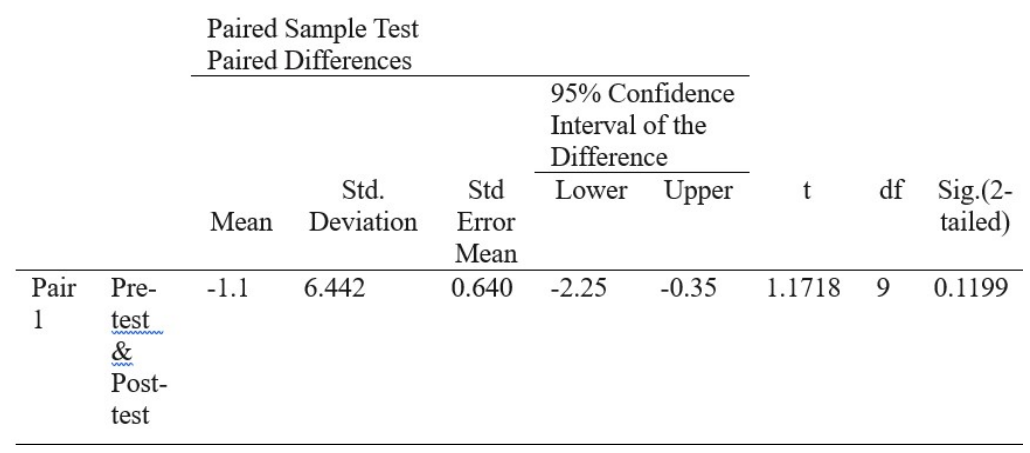

Table 8.0 Mark difference before and after using the proposed game-based learning game from Control Group

According to table 7.0, the SPSS analysis showed the significant value is 0.1199 which less than the standard 0.025 value. Thus, it means there is not statistically significant in pre-test and posttest for the control group. 
The International Journal of Multimedia \& Its Applications (IJMA) Vol.10, No.6, December 2018

\subsection{Analysis of Student Performance in Focus Group}

According to table 9.0, the lowest score and highest score for pre-test is 27 and 42 . As for the lowest and highest score for post-test is 34 and 49 respectively. The lowest score increase in pretest and post-test is 1 that achieved by student S8. All the students from focus group are achieving score increment (100\%). Total of 5 students (S2, S4, S5, S8 and S9) obtained score increment between 1 to 10 scores, 4 students (S1, S3, S7 and S10) obtained score increment between 10 19 scores and only 1 student (S6) obtained score increment more than 20 score.

Table 9.0 Pre-Test and Post-Test result from Focus Group

\begin{tabular}{|c|c|c|}
\hline Student & Pre-Test & Post-Test \\
\hline S1 & 32 & 44 \\
\hline S2 & 42 & 48 \\
\hline S3 & 25 & 36 \\
\hline S4 & 36 & 42 \\
\hline S5 & 35 & 39 \\
\hline S6 & 27 & 49 \\
\hline S7 & 38 & 48 \\
\hline S8 & 34 & 35 \\
\hline S9 & 36 & 34 \\
\hline S10 & 33 & 47 \\
\hline
\end{tabular}

Table 10.0 Paired Sample Statistic for Pre-Test and Post-Test from Focus Group

\begin{tabular}{llllll}
\hline & & \multicolumn{3}{l}{ Paired Sample Statistics } & \\
\cline { 3 - 5 } & & Mean & $\mathrm{N}$ & Std. Deviation & Std. Error Mean \\
\hline Pair 1 & Pre-test & 33.8 & 10 & 4.984 & 1.576 \\
& Post-test & 42.2 & 10 & 5.846 & 1.849 \\
\hline
\end{tabular}

Paired sample t-test is conducted for testing the significant mean score in pre-test and post-test to the focus group. The analysis result of paired sample t-test is shown $\mathrm{n}$ table 10.0. Form the table 10.0 , the mean score for control group is 8.4 (from 33.8 to 42.2 ).

Table 11.0 Paired t-test for Pre-Test and Post-Test from Focus Group

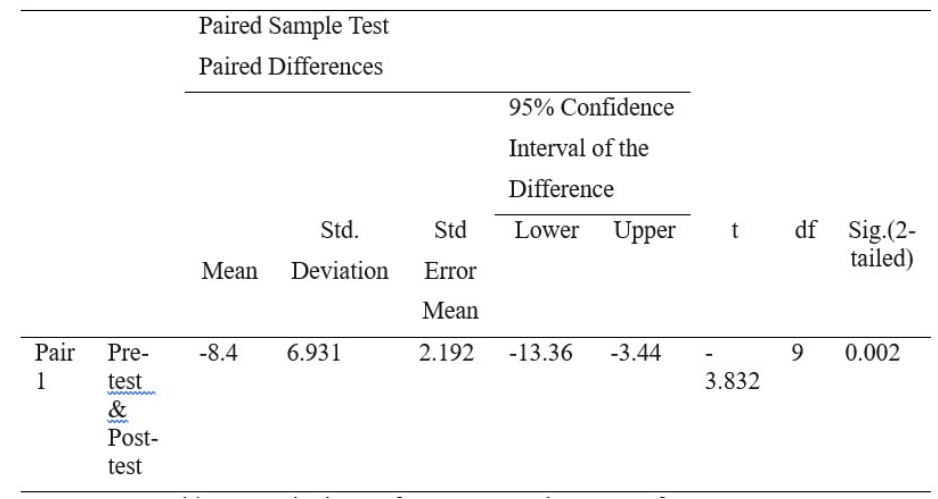

Table 12.0 Mark difference before and after using the proposed game-based learning game from Focus Group 
The International Journal of Multimedia \& Its Applications (IJMA) Vol.10, No.6, December 2018

\begin{tabular}{|l|l|}
\hline Students & $\begin{array}{l}\text { Mark different for } \\
\text { Pre-test and post-test }\end{array}$ \\
\hline S1 & +12 \\
\hline S2 & +6 \\
\hline S3 & +11 \\
\hline S4 & +6 \\
\hline S5 & +4 \\
\hline S6 & +22 \\
\hline S7 & +10 \\
\hline S8 & +1 \\
\hline S9 & -2 \\
\hline S10 & +14 \\
\hline
\end{tabular}

From the table 7.0, the SPSS analysis showed the significant value is 0.002 which less than the standard 0.025 value. Thus, it means there is statistically significant in pre-test and post-test for the Focus group. Result obtained showed that the post-test score was higher than the pre-test score for both group. Besides that, the significant value for both groups also less than 0.025 . However the significant value for focus group less than control group that showed from the above SPSS statistic analysis. The significant value for focus group is 0.0002 compare to the control group significant value is 0.1199 . The huge different showed the focus group that learning objectoriented programming with the proposed game as supportive learning tool is significantly improve the player learning process and understanding.

\subsection{Questionnaire Analysis}

A set of questionnaire that consists of 10 questions was giving to all the participated focus group students. The given questionnaire mainly serves as a platform for the student to comment and provide constructive opinions about the game. First question is to find out the gender of the participated students. According to the data or feedback obtain from the questionnaires, $86 \%$ from the student responded game based learning approach is better than traditional teaching approach. As mentioned user interface design for the game is one of the significant element to provide an effective learning environment, this can be shown by the data obtained which $86 \%$ of the students agreed that the user interface is a significant element for game based learning environment. Another important element for game based learning mentioned is in-game storyboard. There are two way to carry out the in-game storyline to the student which are narrative approach and simulation approach. Based on the response given by the student, $60 \%$ of them prefer simulation approach compare to narrative approach, which is only $40 \%$. Besides that, another major objective for this questionnaire is to find out which game genre is the best for the computer game to teach and learn object-oriented programming. From the participated student response, 50\% of them selected Role Playing Game, 30\% selected Puzzle game and 20\% selected Simulation Game. Besides the quantifiable data, five participated students had been randomly selected to for interview in order to obtain their feedback regarding to the prosed game that developed with Game-based learning framework. In general, all five students are enjoy playing the proposed game-based learning game and agreed on the proposed gameplay able to help them to get better understanding on the Object-Oriented Programming paradigms. Some of the constructive idea to improve the proposed game given by these student as shown below:

- More animation feature and better graphic user interface as motivation for the student to retain focus

- More puzzle games needed to make it more challenging for the students 
The International Journal of Multimedia \& Its Applications (IJMA) Vol.10, No.6, December 2018

- Include more advanced topic of object oriented programming and provide more problem solving based learning example

- Include more fun element by adding more interaction such as surprise facts, reward system and etc.

As a summary, most of the students agreed that the computer game able to meet the learning and teaching objective. Besides that, all of them agreed that game based learning is an effective tool for learning and teaching object oriented programming. The subject experts are satisfied with the proposed game-based learning game.

\section{Conclusion}

The proposed research identified a game-based learning game which covered the OOP paradigm. By making the learning experience and process fun and attractive, the development of OoP encourages the student to learn OOP in a simpler way. The game-based learning was found to be useful as the learning approach for OOP teaching according to the results obtained from the pilot testing. Furthermore, the pilot testing also showed that students were actively learning and applying OOP paradigm according to the game level and the game mechanics. Therefore, OoP has demonstrated its efficiency as a game-based learning tool for tertiary level education. In the future, by combining the novel game-based learning and the traditional teaching practices, the teaching of OOP to students will be more effective and efficient. This is because game-based learning could motivate students to learn OOP topics in a more fun, challenging and engaging environment. The main challenge for this research is to ensure the learning implicit while making the teaching game fun and interesting to retain students' motivation. With regards to those issues, the development of OoP not only addresses those challenges, but also provides a feasible and novel teaching technique to the education field.

\section{REFERENCES}

[1] Brinda, T., Kramer, M., Hubwieser, P., \& Ruf, A. (2015). Towards a Competency Model for ObjectOriented Programming. In Proceedings of the 2015 ACM Conference on Innovation and Technology in Computer Science Education, 345-345.

[2] Rais, A.E., Shahida S., Syed-Mohamad, S.M. (2011). Game-based approach and its feasibility to support the learning of object-oriented concepts and programming. Software Engineering (MySEC), 2011 5th Malaysian Conference in. IEEE.

[3] Wong, Y. S., Hayati, I. M., Yatim, M., \& Hoe, T. W. (2017). A Propriety Game Based Learning Mobile Game to Learn Object-Oriented Programming - Odyssey of Phoenix. Paper presented at the 2017 IEEE 6th International Conference on Teaching, Assessment, and Learning for Engineering (TALE).

[4] Wong, Y. S., \& Hayati, I. M. (2014). Computer Game as Learning and Teaching Tool for Object Oriented Programming in Higher Education Institution. Procedia-Social and Behavioral Sciences, $123,215-224$.

[5] Wong, Y. S., Hayati, M. Y. M., \& Tan, W. H. (2016). A Propriety Game-Based Learning Game as Learning Tool to Learn Object-Oriented Programming Paradigm. In Joint International Conference on Serious Games, Springer International Publishing 42-54.

[6] Vahldick, A., Mendes, A.J., Marcelino, M.J. (2014) A review of games designed to improve introductory computer programming competencies. In Frontiers in Education Conference (FIE), IEEE, 1-7. 
The International Journal of Multimedia \& Its Applications (IJMA) Vol.10, No.6, December 2018

[7] Wong, Y. S., Yatim, M., Hayati, M., \& Tan, W. H. (2014). Use computer game to learn ObjectOriented programming in computer science courses. In Global Engineering Education Conference (EDUCON), 2014 IEEE ,9-16

[8] Mullins, P. M., \& Conlon, M. (2008). Engaging students in programming fundamentals using Alice 2.0. In Proceedings of the 9th ACM SIGITE conference on Information technology education ACM, 81-88.

[9] Kölling, M. (2012). The greenfoot programming environment. ACM Transactions on Computing Education (TOCE), 10(4), 14.

[10] Rodríguez Corral, José María, Civit Balcells, Antón, Morgado Estévez, Arturo, Jiménez Moreno, Gabriel, \& Ferreiro Ramos, María José. (2014). A Game-Based Approach to the Teaching of ObjectOriented Programming Languages. Computers \& Education, 73, 83-92. doi: https://doi.org/10.1016/j.compedu.2013.12.013 .

[11] Helme, S., \& Clarke, D. (2001). Identifying cognitive engagement in mathematics classroom. Mathematics Education Research Journal, 13, 133-153.

[12] Csikszentmihalyi, M. (1975). Play and intrinsic rewards. Journal of humanistic psychology. 15(3), 4163.

[13] Kazimoglu, C., Kiernan, M., Bacon, L., \& Mackinnon, L. (2012). A serious game for developing computational thinking and learning introductory computer programming. Procedia-Social and Behavioral Sciences, 47.

[14] Keller, J.M. (2009). Motivational design for learning and performance: The ARCS model approach. Springer Science \& Business Media.

[15] Siang, A.C., Rao, R.K, December. Theories of learning: a computer game perspective. In Multimedia Software Engineering, (2003). Proceedings. Fifth International Symposium on 2003 (pp. 239-245). IEEE.

[16] Deci, E.L. Ryan, R.M. (2011). Self-determination theory. Handbook of theories of social psychology, $1,416-433$.

[17] Reynolds, G..S. (1975). A primer of operant conditioning. University of California: Scott, Foresman \& Company.

[18] Collins, A. (1991). Educational values and cognitive instruction: Implications for reform, Cognitive apprenticeship and instructional technology

[19] Tulving, E. (1985). Elements of episodic memory. Oxford: Oxford University Press.

[20] Klump, R. (2001). Understanding object-oriented programming concepts. In Power Engineering Society Summer Meeting IEEE, 2, 1070-1074.

[21] Wong, Y. S., \& Tan, W. H. (2016). Examining Effectiveness of Learning Object-Oriented Programming Paradigm through Propriety Game-Based Learning Games. In European Conference on Games Based Learning, Academic Conferences International Limited, 796.

[22] Tang, S., \& Hanneghan, M. (2014). Designing educational games: a pedagogical approach. Gamification for Human Factors Integration: Social, Education, and Psychological. Social, Education, and Psychological Issues, 181-198.

[23] Asselin, M. E., \& Fain, J. A. (2013). Effect of reflective practice education on self-reflection, insight, and reflective thinking among experienced nurses: A pilot study. Journal for nurses in professional development, 29(3), 111-119.

[24] Cook, D. A., Beckman, T. J., Thomas, K. G., \& Thompson, W. G. (2009). Measuring motivational characteristics of courses: applying Keller's instructional materials motivation survey to a web-based course. Academic Medicine, 84(11), 1505-1509.

[25] Dieker, Lisa A, Rodriguez, Jacqueline A, Lignugaris/Kraft, Benjamin, Hynes, Michael C, \& Hughes, Charles E. (2014). The Potential of Simulated Environments in Teacher Education: Current and Future Possibilities. Teacher Education and Special Education, 37(1), 21-33

[26] Plass, J. L., Homer, B. D., \& Kinzer, C. K. (2015). Foundations of game-based learning. Educational Psychologist, 50(4), 258-283

[27] Biggs, J. (1996). Enhancing teaching through constructive alignment. Higher education, 32(3), 347364. 
The International Journal of Multimedia \& Its Applications (IJMA) Vol.10, No.6, December 2018

[28] Biggs, J. (1987) Student approaches to learning and studying, Hawthorn, Vic: Australian Council for Educational Research Limited.

[29] Prensky, M. (2005). Engage Me or Enrage Me: What Today's Learners Demand. Educause review, 40(5), 60.

[30] Cohen, L., Manion, L., \& Morrison, K. (2013). Research methods in education. Routledge.

\section{AUTHORS}

Jason Wong is a Senior Lecturer at KDU University College, Malaysia. He received a B.S degree in Information System Engineering from Campbell University and M.S.C in Computer Game Technology from Liverpool John Moores University, UK. He has been teaching game design and game programming related subject for over 12 years and actively involved in game related research projects. His current research involves using computer game as learning tool for learning object-oriented programming in tertiary level.

Maizatul Hayati Mohamad Yatim is an associate professor and faculty Dean at Faculty of Art, Computing and Creative Industry, Sultan Idris Education University (UPSI). Her research interest is in Human-Computer Interaction, IT Project Management, Multimedia in Education, Edutainment and Children and Games Design \& Development.

Tan Wee Hoe is an associate professor at Faculty of Art, Computing and Creative Industry, Sultan Idris Education University (UPSI). His research interest is in Game production (design \& production management); Game-based learning \& learn-based gaming strategies; Animation Production (methods \& technologies); E-Learning Technologies; Instructional System Design; Application of Sun Tzu's The Art of War principles in research (academic \& commercial), teaching \& learning.
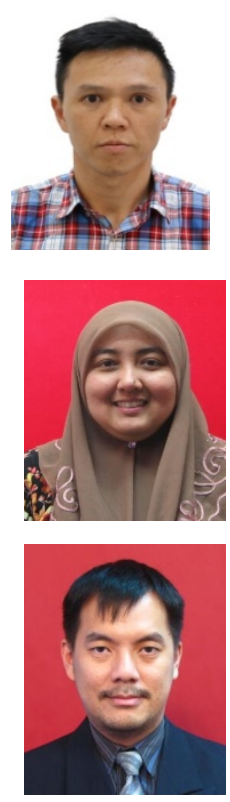